\title{
PERINATAL INFECTIONS IN UKRAINE: RESULTS OF A MULTICENTER STUDY
}

DOI: 10.36740/WLek202109101

\author{
Aidyn G. Salmanov ${ }^{1,2}$, Oleg M. Ishchak ${ }^{3}$, Serhii A. Dobarin ${ }^{4}$, Olena M. Susidko $^{5}$, Olena V. Mosendz ${ }^{6}$, \\ Svitlana M. Korniyenko ${ }^{7}$, Oleksandr A. Voloshyn ${ }^{8}$ \\ 'SHUPYK NATIONAL HEALTHCARE UNIVERSITY OF UKRAINE, KYIV, UKRAINE \\ 2INSTITUTE OF PEDIATRICS, OBSTETRICS AND GYNECOLOGY OF THE NATIONAL ACADEMY OF MEDICAL SCIENCES OF UKRAINE, KYIV, UKRAINE \\ ${ }^{3}$ TERNOPIL PERINATAL CENTER, TERNOPIL, UKRAINE \\ ${ }^{4}$ KIEV CITY MATERNITY HOSPITAL № 5, KYIV, UKRAINE \\ ${ }^{5}$ DOCTOR NIKOLAEV MEDICAL CENTER, DNIPRO, UKRAINE \\ ${ }^{6}$ MEDICAL CENTRE MEDISVIT, KYIV, UKRAINE \\ ${ }^{7}$ ODESA NATIONAL MEDICAL UNIVERSITY, ODESA, UKRAINE \\ ${ }^{8}$ KYIV REGIONAL MATERNITY HOSPITAL, KYIV, UKRAINE
}

\begin{abstract}
The aim: To obtain the estimates of the current incidence rate of perinatal infections, risk factors, as well as their associated impact on mortality and determine the antimicrobial resistance of responsible pathogens in Ukraine.

Materials and methods: We performed a multicentre retrospective cohort study was based on surveillance data. This study included infants aged 0 to 6 days delivered in 2017-2019 at 11 Ukrainian regional perinatal centers. Definitions of perinatal infections and mortality were used from the CDC/WH0/UNICEF.

Results: 0 18,348 liveborn infants, 472 (2.6\%) perinatal infections were detected. The incidence of perinatal infection was 25.7 per 1000 live births. The most frequently identified types of infections were: bloodstream infections, $35.6 \%$, lower respiratory tract infections, $21.4 \%$, Meningitis, 18.2\%, Conjunctivitis, $11.9 \%$, skin and soft tissue infections, $6.6 \%$, Dacryocystitis, 3.8\%, and urinary tract infections, $2.5 \%$. Early mortality rates from perinatai infections was $51.1 \%$, with an incidence of 13.1 deaths $/ 1000$ live births. Potential risk factors the development of perinatal infections and mortality were low birth weight, prematurity, low gestasional age, mode of delivery (manual aid), premature rupture of membranes, preterm premature rupture of membranes, prolonged rupture of membranes, turbid and meconeal amniotic fluid, infection of the mother during labor. resuscitation during delivery, invasive procedure, asphyxia. Main causative agents of perinatal infections were Escherichia coli, Streptococcus agalactiae, Staphylococcus aureus, Klebsiella pneumoniae, CoNS, Enterobacter cloacae, Pseudomonas aeruginosa.

Conclusions: This study showing that the high incidence rate of perinatal bacterial infections, as well as their associated impact on mortality, and presents a significant burden to the Ukraine.
\end{abstract}

KEY WORDS: perinatal infections, mortality, risk factors, bacterial pathogens, antimicrobial resisnance

Wiad Lek. 2021;74(9 p.l):2025-2032

\section{INTRODUCTION}

Neonatal morbidity and mortality are major global public health problem [1]. One of the causes of morbidity and mortality in newborns and child are is infections. As overall infant and child mortality fall, neonatal mortality represent an increasing proportion with recent estimates showing that neonatal mortality now accounts for more than $40 \%$. Approximately 3.1 million babies worldwide dying each year in the first month of life [2,3]. The latest Levels and Trends in Child Mortality: Report 2020 from UNICEF and partners in the UN Inter-Agency Group for Child Mortality Estimation (UN IGME), shows the while mortality rates across age groups have continued to decline, the numbers of child deaths remain high -5 million children age 5 died in 2019 alone largely due to causes such as infectious diseases, and nearly half of those deaths were among newborns (birth to 28 days of age) [4].
According to WHO, although the global number of newborns deaths declined from 5 million in 1990 to 2.4 million in 2019, children face the greatest risk of death in their first 28 days. There are approximately 6700 newborn deaths every day, amounting to $47 \%$ of all child deaths under the age of 5-years, up from $40 \%$ in 1990 . In 2019 , $47 \%$ of all under- 5 deaths occurred in the newborn period with about one third dying on the day of birth and close to three quarters dying within the first week of life [5]. Preterm birth, intrapartum-related complications (birth asphyxia or lack of breathing at birth), infections and birth defects cause most neonatal deaths. [5]. Neonatal infection is an important cause of morbidity, prolonged hospital stay and mortality among infants [6]. These infections are representing major causes of permanent disability among children worldwide [7]. 
Due to the immaturity of the immune system, newborn infants are at risk for neonatal infections with certain viruses and several bacteria. [7]. An infection caused by a bacteria or virus that can be passed from a mother to to the infant during pregnancy (prenatal or congenital infections) or childbirth (perinatal or intranatal infections), as well as immediately after birth (postnatal infections) is called a perinatal infection. Maternal bacterial infection or colonization can, in some cases, cause complications at birth. Transmission of many bacterial perinatal infections occurs during childbirth, particularly in cases when invasive techniques such as episiotomy or artificial rupture of membranes are employed. Pathogens causing neonatal infections and their antibiotic susceptibility patterns may change over time and differ between countries [8-10]. It is therefore essential to monitor the epidemiology of neonatal infections to inform policy and clinical practice.

Although neonatal infections causes a significant proportion of deaths in the first week of life, little is known about the prevalence of bacterial neonatal disease originating from maternal infection or colonization. For most bacterial pathogens, the mechanism leading to early-onset neonatal infection in newborns is unknown. In Ukraine, neonatal morbidity and mortality in infants which early-onset bacterial infections and pathogens causing neonatal infections and their antibiotic susceptibility is unknown. Neonatal infection surveillance networks not been established in Ukraine. There are few published data of neonatal mortality and morbidity in the Ukraine. In addition, these studies have mainly focused only on specific causes of neonatal morbidity. Therefore, more research study is needed to assess the prevalence of early-onset bacterial infections in infants.

\section{THE AIM}

To obtain the estimates of the current incidence rate of perinatal infections, risk factors, as well as their associated impact on mortality and determine the antimicrobial resistance of responsible pathogens in Ukraine.

\section{MATERIALS AND METHODS}

\section{SETTING AND PARTICIPANTS}

We performed a multicentre retrospective cohort study was based on surveillance data. This study included all infants aged 0 to 6 days delivered in 2017-2019 at 11 Ukrainian regional perinatal centers, which are similar in terms of medical equipment, personnel, laboratory facilities, and number of beds. All participating hospitals were required to have a clinical microbiology laboratory with the capacity to process cultures. Inclusion criteria: all mothers were local residents. Infants who were referred from other hospitals were excluded. Also excluded are babies born by caesarean section.

\section{DEFINITIONS}

We defined perinatal infection during the first seven days of life. Live birth is defined as complete expulsion or ex- traction from the mother of a product of human conception, irrespective of the duration of pregnancy, which shows any evidence of life (ie, heartbeats, umbilical cord pulsations, breathing, or voluntary muscle movement), regardless of whether the umbilical cord has been cut or the placenta is attached. Prematurity are liveborn infants delivered before 37 weeks of pregnancy (based on the Ballard score or from first day of the last menstrual period). Low birth weight (LBW) neonate is neonate whose birth weight is less than 2,500 gram. Meconeal amniotic fluid was considered if the amniotic fluid was green in color or mixed with meconeal, or appears meconeal stained in the baby. Congenital anomaly is defined as any abnormality of anatomy and morphology that found during physical examination. Premature rupture of membrane (PROM) is defined as the time from membrane rupture to onset of delivery was more than 18 hour. Asphyxia is defined as Apgar score less than 3 in the five minutes from delivery. For the purposes of this study an infection caused by bacteria that can be passed from a mother to her baby during pregnancy or delivery is called a perinatal infection. We used common criteria for three separate definitions for neonatal blood stream infections (BSI), meningitis and lower respiratory tract infections (LRTI) [11]. Early onset sepsis (EOS) was defined as infection in the first $48 \mathrm{~h}$ of life and late onset sepsis (LOS) as infection occurring thereafter. For definitions of Conjunctivitis, Dacryocystitis, Urinary Tract Infections (UTIs), Skin and Soft Tissue Infections (SSTIs) in Newborns used criteria by CDC. In our study the perinatal mortality rate encompasses early neonatal mortality.Early neonatal mortality rate: deaths at 0-6 days after live birth $x$ $1000 /$ live births $[12,13]$.

\section{DATA COLLECTION}

We reviewed data of all live births and collected the data of sample characteristic such as sex, gestational age, birth weight, mode of delivery and outcome between 2018 and 2020 were collected on a form specifically designed by the investigators using medical records comprising charts, daily flow sheets. A standardised form was completed by the clinician for each positive culture, and included the infant's demographic details (birth weight, gestational age, gender), clinical information and microbiological data, as well as the antibiotic resistance profile of the isolate. Cases of perinatal infections that met standard case definitions were identified through active follow up during the hospital stay, on return to hospital, and during visits to ambulatory. Infants were followed through the patient records system to determine the rate of complications (mortality and morbidity). Anonymised data were then transferred onto a remote Microsoft Excel database. Data were cross-checked against the local microbiology databases on a regular basis to ensure completeness.

\section{ETHICS}

The Shupyk National Healthcare University of Ukraine Ethics Committee approved the waiver of informed consent to participate in this study due to its retrospective design. All 
infants data were anonymised prior to the analysis. Infants presenting in this study were enrolled with due consent of their parents. Informed consent was obtained from the mother of the neonate before enrollment in the study.

\section{MICROBIOLOGICAL METHODS}

All samples were obtained from infants with clinical symptoms of perinatal infections. Bacterial isolates were identified using standard microbiological techniques, including automated microbiology testing. Antibiotic susceptibility testing was performed by using the disk diffusion method according to the recommendations of the EUCAST. In our study strains in the intermediate range were classified as resistant for data analysis

\section{STATISTICAL ANALYSIS}

The analysis of statistical data was performed using Excel. Results are expressed as median (range), mean standard deviation for continuous variables, and number and corresponding percentage for qualitative variables. Comparisons were undertaken using Student's t-test and Fisher's exact test for categorical variables. Statistical significance was defined as $P<0.05$.

\section{RESULTS}

\section{PERINATAL INFECTIONS}

During the study period (January 1st, 2017 and December 31 st, 2019), of the 18,348 liveborn infants included in the study, perinatal infections was diagnosed in 472 (2.6\%, 95\% CI $2.5 \%, 2.7 \%, P<0.001)$. The incidence of perinatal infection was 25.7 per 1000 live births $(472 / 18,348)$. The most frequently identified types of perinatal infections was the following: BSIs, $35.6 \%$ (95\% confidence interval [CI], 35.2-35.9), LRTI, $21.4 \%$ (95\% CI, 21.4-21.7), Meningitis, 18.2\% (95\% CI, 17.9-18.5), Conjunctivitis, 11.9\% (95\% CI, 11.7-12.1), SSTIs, 6.6\% (95\% CI, 6.4-6.8), Dacryocystitis, 3.8\% (95\% CI, 3.7-3.9), and UTI, 2.5\% (95\% CI, 2.4-2.6) (Table I). This study showed that the incidence of perinatal infection was higher in 2019 than in 2017 (25.7 vs. 21.4 per 1000 live births). The incidence rate (per 1000 live births) of perinatal infections among live births in Ukraine is shown in Table II.

Perinatal infection was more common in male $(\mathrm{n}=265$, $56,1 \%)$ than in female infants $(\mathrm{n}=207,43.9 \% ; p=0.0001)$. The distribution of characteristic samples between perinatal infections and non infection cases; the birth weight in perinatal infection cases were also significantly lower than non infection cases. In addition, there were differences in the mode of delivery between two groups (infection and no infection). The majority of episodes of infection $(n=334$, $70.8 \%, p=0.0001$ ) occurred in infants born at $<37$ weeks gestation. In addition, there were differences in the mode of delivery between two groups (infection and no infection), in premature rupture of the membrane, in turbid and meconeal amniotic fluid, and in asphyxia. Similarly, 98.2\% of episodes occurred in infants with a birth weight $<2000 \mathrm{~g}(\mathrm{n}=347)$, of which $53 \%(\mathrm{n}=237)$ occurred in infants $<1000 \mathrm{~g}, 47.3 \%(\mathrm{n}=164)$. (Table III).

Approximately a quarter $(24.2 \%)$ of all perinatal infections occurred in the first $48 \mathrm{~h}$ of life (early onset) and the

Table I. The frequently identified types of infections among 472 infants with perinatal infections in Ukraine, 2017-2019

\begin{tabular}{ccc}
\hline Type of infections & No. of infections & $\%(\mathbf{9 5} \% \mathbf{C I})$ \\
\hline BSIs & 168 & $35.6(35.2-35.9)$ \\
\hline LRTI & 101 & $21.4(21.1-21.7)$ \\
\hline Meningitis & 86 & $18.2(17.9-18.5)$ \\
\hline Conjunctivitis & 56 & $11.9(11.7-12.1)$ \\
\hline SSTls & 31 & $6.6(6.4-6.8)$ \\
\hline Dacryocystitis & 18 & $3.8(3.7-3.9)$ \\
\hline UTIs & 12 & $2.5(2.4-2.6)$ \\
\hline
\end{tabular}

BSI, bloodstream infection; LRTI, lower respiratory tract infections; SSTI, skin and soft tissue infections; UTI, urinary tract infection; $\mathrm{Cl}$, confidence interval.

Table II. The incidence of perinatal infections among 18,348 liveborn infants in Ukraine, 2017-2019

\begin{tabular}{cccc}
\hline Type of infections & Number of cases & Incidence rate per $\mathbf{1 0 0 0}$ live births & 95\% CI \\
\hline BSIs & 168 & 9.2 & $9.0-9.4$ \\
\hline LRTI & 101 & 5.5 & $5.3-5.7$ \\
\hline Meningitis & 86 & 4.7 & $4.5-4.9$ \\
\hline Conjunctivitis & 56 & 3.1 & $3.0-3.2$ \\
\hline SSTIs & 31 & 1.7 & $1.6-1.8$ \\
\hline Dacryocystitis & 18 & 1.0 & $0.9-1.1$ \\
\hline UTIs & 12 & 0.7 & $0.6-0.8$ \\
\hline
\end{tabular}

BSI, bloodstream infection; LRTI, lower respiratory tract infections; SSTI, skin and soft tissue infections; UTI, urinary tract infection; $\mathrm{Cl}$, confidence interval. 
Aidyn G. Salmanov et al.

Table III. Characteristics of liveborn infants with and without perinatal infections in Ukraine, 2017-2019

\begin{tabular}{|c|c|c|c|c|}
\hline \multirow[b]{2}{*}{ Characteristics } & \multirow{2}{*}{$\begin{array}{c}\text { All infants } \\
\text { n (\%) }\end{array}$} & \multicolumn{2}{|c|}{ Perinatal infections } & \multirow[b]{2}{*}{ p value } \\
\hline & & $\begin{array}{c}\text { Yes } \\
\text { n (\%) }\end{array}$ & $\begin{array}{c}\text { No } \\
n(\%)\end{array}$ & \\
\hline All & $18348(100)$ & $472(2.6)$ & $17876(97.4)$ & \\
\hline Sex: & & & & 0.0001 \\
\hline Male & $8672(47.3)$ & $265(56.1)$ & $8407(47.0)$ & \\
\hline Female & $9676(52.7)$ & 207 (43.9) & $9469(53.0)$ & \\
\hline Birth weight (g) & & & & 0.0001 \\
\hline$<1000$ & $218(1.2)$ & $164(75.2)$ & $54(24.8)$ & \\
\hline 1000-1499 & $1192(6.5)$ & $118(9.9)$ & $1074(90.1)$ & \\
\hline $1500-2000$ & $1907(10.4)$ & $65(3.4)$ & $1842(96.6)$ & \\
\hline $2000-2500$ & $3202(17.5)$ & $31(1.0)$ & $3171(99.0)$ & \\
\hline$>2500$ & $11829(64.5)$ & $94(0.8)$ & $11735(99.2)$ & \\
\hline Gestasional age: & & & & 0.0001 \\
\hline Premature & $5226(28.5)$ & $334(70.8)$ & $4892(27.4)$ & \\
\hline Aterm & $13122(71.5)$ & $138(29.2)$ & $12984(72.6)$ & \\
\hline Mode of delivery: & & & & 0.004 \\
\hline Spontaneous & $6317(34.4)$ & $96(20.3)$ & $6221(34.8)$ & \\
\hline Breech delivery & $9344(50.9)$ & $122(25.8)$ & $9222(51.6)$ & \\
\hline Manual aid & $2687(14.6)$ & $254(53.8)$ & $2433(13.6)$ & \\
\hline PROM & & & & 0.0001 \\
\hline Yes & $3091(16.8)$ & $312(66.1)$ & $2779(15.5)$ & \\
\hline No & $15257(83.2)$ & $160(33.9)$ & $15097(84.5)$ & \\
\hline PPROM & & & & 0.0001 \\
\hline Yes & $2836(15.5)$ & $334(70.8)$ & $2502(8.4)$ & \\
\hline No & $15512(84.5)$ & $138(29.2)$ & $15374(91.6)$ & \\
\hline Prolonged rupture of membranes & & & & 0.0001 \\
\hline Yes & $4783(26.1)$ & $337(71.4)$ & $4446(24.9)$ & \\
\hline No & $13565(73.9)$ & $135(28.6)$ & $13430(75.1)$ & \\
\hline TMAF & & & & 0.0001 \\
\hline Yes & $1827(10.0)$ & $321(68.0)$ & $1506(8.4)$ & \\
\hline No & $16521(90.0)$ & $151(32.0)$ & $16370(91.6)$ & \\
\hline Infection of the mother during labor & & & & 0.0001 \\
\hline Yes & $1827(10.0)$ & $321(68.0)$ & $1506(8.4)$ & \\
\hline No & $16521(90.0)$ & $151(32.0)$ & $16370(91.6)$ & \\
\hline Resuscitation during delivery & & & & 0.0002 \\
\hline Yes & $2133(11.6)$ & $331(70.1)$ & $1802(10.1)$ & \\
\hline No & $16215(88.4)$ & $141(29.9)$ & $16074(89.9)$ & \\
\hline Invasive procedure & & & & 0.0001 \\
\hline Yes & $6187(33.7)$ & $376(79.7)$ & $5811(32.5)$ & \\
\hline No & $12161(66.3)$ & $96(20.3)$ & $12065(67.5)$ & \\
\hline Asphyxia & & & & 0.004 \\
\hline Yes & $2376(12.9)$ & $289(61.2)$ & $2087(11.7)$ & \\
\hline No & $15972(87.1)$ & $183(38.8)$ & $15789(88.3)$ & \\
\hline Congenital anomaly & & & & 0.006 \\
\hline Yes & $987(5.4)$ & $244(51.7)$ & $743(4.2)$ & \\
\hline No & $17361(94.6)$ & $228(48.3)$ & $17133(95.8)$ & \\
\hline
\end{tabular}

PROM, premature rupture of membranes; PPROM, preterm premature rupture of membranes; TMAF, turbid and meconeal amniotic fluid. 
Table IV. The incidence rate of perinatal infection and mortality among 18348 infants in Ukraine, 2017-2019

\begin{tabular}{|c|c|c|c|c|}
\hline \multirow[b]{2}{*}{ Type of infections } & \multirow{2}{*}{$\begin{array}{c}\text { Number of } \\
\text { infection cases }\end{array}$} & \multicolumn{2}{|c|}{ Mortality } & \multirow[b]{2}{*}{$95 \% \mathrm{Cl}$} \\
\hline & & n (\%) & $\begin{array}{c}\text { Incidence } \\
\text { per } 1000 \text { live births }\end{array}$ & \\
\hline All infections & 472 & $241(51.1)$ & 13.1 & $12.8-13.4$ \\
\hline BSIs & 168 & $148(88.1)$ & 8.1 & $7.9-8.3$ \\
\hline LRTI & 101 & $65(64.4)$ & 3.5 & $3.4-3.6$ \\
\hline Meningitis & 86 & $28(32.6)$ & 1.5 & $1.4-1.6$ \\
\hline Conjunctivitis & 56 & 0 & 0 & 0 \\
\hline SSTIS & 31 & 0 & 0 & 0 \\
\hline Dacryocystitis & 18 & 0 & 0 & 0 \\
\hline UTIs & 12 & 0 & 0 & 0 \\
\hline
\end{tabular}

BSI, bloodstream infection; LRTI, lower respiratory tract infections; SSTI, skin and soft tissue infections; UTI, urinary tract infection; $\mathrm{Cl}$, confidence interval.

Table V. Most common pathogens ( $\mathrm{n}=14987)$ causing perinatal infections in Ukraine, 2017-2019

\begin{tabular}{|c|c|c|}
\hline \multirow{2}{*}{ Pathogens } & \multicolumn{2}{|c|}{ All isolates } \\
\hline & $\mathbf{n}$ & $\%$ \\
\hline Gram-positive cocci & 5783 & 38.6 \\
\hline Streptococcus agalactiae & 1983 & 13,2 \\
\hline Streptococcus pyogenes & 284 & 1,9 \\
\hline Streptococcus pneumoniae & 503 & 3,4 \\
\hline Enterococcus spp. & 511 & 3,4 \\
\hline Staphylococcus aureus & 1344 & 9,0 \\
\hline CoNS & 1079 & 7,2 \\
\hline Other Gram-positive cocci & 79 & 0,5 \\
\hline Gram-negative bacilli & 9204 & 61.4 \\
\hline Escherichia coli & 2873 & 19,2 \\
\hline Enterobacter cloacae & 984 & 6,6 \\
\hline Klebsiella pneumoniae & 1187 & 7,9 \\
\hline Serratia marcescens & 811 & 5,4 \\
\hline Pseudomonas aeruginosa & 987 & 6,6 \\
\hline Haemophilus influenzae & 143 & 1,0 \\
\hline Proteus mirabilis & 278 & 1,9 \\
\hline Citrobacter freundii & 503 & 3,4 \\
\hline Klebsiella oxytoka & 511 & 3,4 \\
\hline Acinetobacter spp. & 736 & 4,9 \\
\hline Bacteroides spp. & 112 & 0,7 \\
\hline Other Gram-negative bacilli & 79 & 0,5 \\
\hline
\end{tabular}

CoNS, Coagulase negative staphylococci

majority of these occurred on the first day (83.9\%). Of all late onset infections, $19.3 \%$ occurred between days 3 and 7 of life. Almost one half of infections on day 1 occurred in infants over $2500 \mathrm{~g}(47.2 \%)$ and $59.8 \%$ occurred in infants of 32 weeks gestation or above. The incidence rate of sepsis in during study period was 9.2 per 1000 live births $(168 / 18,348)$. Early onset sepsis ( $\leq 48 \mathrm{~h}$ of age) incidence was 5.3 per 1000 live births and late onset sepsis $(>48 \mathrm{~h}$ of age) was 3.9 per 1000 live births. The median age at infection was 4 days of life and the majority of episodes $(71.3 \%)$ occurred in extremely premature infants $(81.9 \%$ were $<37$ weeks gestation).

\section{RISK FACTORS}

The risk factors that had been analyzed in this study were as follow birth weight, gestasional age, mode of delivery, premature rupture of membranes (PROM), preterm 
premature rupture of membranes (PPROM), prolonged rupture of membranes, turbid and meconeal amniotic fluid, resuscitation during delivery, invasive procedure, asphyxia, and congenital malformation (anomaly). After analyzing results this study, we found that the development of perinatal infections is influenced by both maternal and neonatal risk factors.

In this study, maternal risk factors was PROM, PPROM, prolonged rupture of membranes, mode of delivery (manual aid), foul smell of amniotic fluid, turbidity, meconeal amniotic fluid, and infection of the mother during labor. Potential neonatal risk factors that significantly cause of infections were prematurity, low birth weight (LBW), invasive procedure, asphyxia, resuscitation during delivery, congenital anomaly. But the significant risk factors were LBW and prematurity. The risk factors which showed significant differences were analyzed by logistic regression analysis showed there were statistically significant association between the incidence of perinatal infections and risk factors.

\section{PERINATAL MORTALITY}

During study period of the 472 perinatal infections case-infants identified, 241 (51.1\%) is died. The incidence rate of mortality among 18,348 infants included in the study was 13.1 per 1000 live births. Following adjustment for confounding factors, we found that infants with perinatal infections had a significantly increased mortality risk compared to infants without infections. The highest mortality risk was observed in patients with BSI, followed by infants with LRTI and Meningitis. No increased risk of death was found in patients with Conjunctivitis, SSTIs, Dacryocystitis, and UTI (Table IV).

We found that as birth weight increases and gestational age (weeks), the neonatal mortality rate decreases. Key risk factors for perinatal mortality were low or high birth weight, prematurity and post maturity. The mortality was higher among male than female. Mortality rate in the sepsis cases were high (88.1\%). In our study, Gram-negative organisms were the leading cause of death in neonates with EOS and LOS. In EOS, the only bacterial agents, causing mortality that were isolated from the neonates who died were Gram-negative bacteria, whereas in LOS, the most frequent organisms causing mortality isolated were Gram-negative bacteria followed by Gram-positive bacteria. Analysis of organisms isolated in deaths showed that among newborns with EOS, E. coli was isolated in $18 \%$ of cases as a microorganism causing mortality, and Klebsiella and P. aeruginosa were isolated in $11 \%$ and 6,7\% of cases. Among infants with LOS, the most frequent microorganism causing mortality was P. aeruginosa in $15.1 \%$ of cases, followed by $E$. coli in $11.7 \%$ of cases.

\section{PATHOGENS AND ANTIMICROBIAL RESISNANCE}

Our study, only $81.7 \%(14987 / 18348)$ cultures showed growth of different bacteria. Main causative agents of perinatal infections were Escherichia coli, Streptococcus agalactiae, Staphylococcus aureus, Klebsiella pneumoniae, Coagulase negative staphylococci (CoNS), Enterobacter cloacae, Pseudomonas aeruginosa. The type and frequency of isolated pathogen of perinatal infections were shown in Table V. Gram-positive bacteria were responsible for most cases of neonatal sepsis. Most of the bacterial isolates had low sensitivity to the commonly used empiric antibiotics. Best sensitivities among Gram-positive isolates were found against ciprofloxacin, vancomycin, and amikacin. Gram-positive bacteria showed high resistance to ampicillin (91.5\%). The intermediate effect was observed (53.5\%) with amoxicillin-clavulanic acid. In contrast to gentamicin, amikacin was highly effective on Gram-positive isolates. Best sensitivity was also observed to ciprofloxacin. Gram-negative bacteria were highly resistant to the firstand second-line empiric antibiotics: ampicillin (89.7\%), amoxicillin-clavulanic acid (91.3\%), gentamicin (68.9\%) and amikacin (71.3\%), and 3rd generation cephalosporins (79.6\%). Best sensitivity was observed to imipenem and ciprofloxacin.

\section{DISCUSSION}

To our knowledge, this study was thefirst attempt to assess the overall burden of perinatal infections in Ukraine. We estimate that perinatal infections are encountered with an average incidence of 25.7 per 1000 live births, and the prevalence of the 7 most frequently recorded types of infections was for the following: BSI, $35.6 \%$, LRTI, $21.4 \%$, Meningitis, $18.2 \%$, Conjunctivitis, $11.9 \%$, SSTIs, $6.6 \%$, Dacryocystitis, $3.8 \%$, and UTI, $2.5 \%$. Mortality from perinatai infections was $51.1 \%$, with an incidence of 13.1 deaths/ 1000 live births (95\% CI, 12.8\% -13.4\%). The highest mortality risk was observed in patients with BSI (88.1\%), followed by infants with LRTI (64.4\%) and Meningitis (32.6\%). No increased risk of death was found in patients with Conjunctivitis, SSTIs, Dacryocystitis, and UTIs. The results our study showed that potential risk factors the development of perinatal infections and mortality in Ukraine are low birth weight, prematurity, low gestasional age, mode of delivery (manual aid), premature rupture of membranes, preterm premature rupture of membranes, prolonged rupture of membranes, turbid and meconeal amniotic fluid, infection of the mother during labor. resuscitation during delivery, invasive procedure, asphyxia.

Few comparable studies of the burden of perinatal infections have been performed to date, with most conducted at the regional or single-center level. Although the estimates in these studies appear similar, the duration of follow-up, frequency of assessment, and clinical algorithms are different. In addition, most studies assessing the impact of perinatal infections have been primarily conducted in ICUs $[10,14]$ or have focused on a single type of infection [9, 15-17] and/or resistance phenotype [14].

Perinatal neonatal mortality rate vary widely and may be below 10 per 1,000 live births for certain developed countries $[18,19]$ and more than 10 times higher in developing countries $[1,20]$. According the official data, early neonatal 
mortality rate in Ukraine, recalculated according to WHO criteria, decreased by 3.1 times - from 4.71 per 1,000 live and dead births in 2000 to 2.99 in 2018 [21]. However, in our study the early neonatal mortality rates for 2019 were essentially unchanged from 2017 (12.96 and 13.19 per 1000 live births, respectively).

In our study, we found that the main causative agents of perinatal infections are E. coli, S. agalactiae, S. aureus, K. pneumoniae, CoNS, Enterobacter spp. and P. aeruginosa, which is in comparable with the findings by other studies $[22,23]$. A high prevalence of bacteria resistant to multiple antibiotics was reported with up to $20 \%$ of gram-negative rods resistant to the broad spectrum antibiotic, Imipenem $[24,25]$.

This study identified a high perinatal morbidity and mortality of newborns caused by bacterial pathogens in Ukraine. The high incidence of perinatal infections is associated with infection of newborns during the passage of the birth canal. Although effective and simple interventions for prevention and treatment of newborn infections exist, they do not reach the majority of neonates in Ukraine. This demonstrates that current recommendations for infection control measures during childbirth are not properly followed. For most of the bacterial pathogens the mechanism that leads to perinatal morbidity and mortality is unknown. One of the main reasons for the high rates of perinatal infection and mortality in Ukraine is the lack of knowledge on how to implement existing infection control measures at scale in resource-limited settings. This knowledge gap can only be filled with appropriate targeted research.

Perinatal infection surveillance networks are necessary for defining the epidemiology of infections and monitoring changes over time [24]. Routinely data collection on perinatal infection, including epidemiological data on cases and associated risk factors, would improve the understanding of determine the need for further surveillance and control measures. Further research is required to clarify of the bacterial pathogens the mechanism that leads to perinatal morbidity and mortality in newborns which perinatal infections. To reduce the incidence of perinatal infections and mortality in newborns infants, it is necessary to determine causative pathogens, and the patterns and rates of antimicrobial resistance.Appropriate identification of the perinatal infections source and management can prevent adverse events following infections.

Currently, neonatal infection surveillance networks have been established in several countries (Australasia, Israel, Canadia, US, Germany, England other) and are useful for documenting changes in clinical practice, benchmarking, monitoring changes in pathogens and their antibiotic resistance over time, informing policy and improving quality of care.

\section{STRENGTHS AND LIMITATIONS}

The absence of national surveillance network in Ukraine compelled us to rely entirely on data from the only existing multicenter survey to assess the burden of perinatal infec- tions. Our study has two limitations. Firstly, the causative agents of perinatal infections are viruses, bacteria, fungi and parasitic agents. However, we only studied bacterial agents. Secondly, mother to baby transmission of infection can occur in utero (congenital), at and around the time of delivery (perinatal) or subsequently (postnatal) as illustrated by transmission of organisms by breastfeeding. However, we studied only bacterial infections that are transmitted during childbirth.

The strengths of the study lie in the a multicentre cohort study was based on surveillance data.It is well known that indicators of perinatal infections provided by surveillance activities require comparison with adequate reference data to stimulate further infection control actions and to enhance quality of care.

More data are clearly needed from the other regions, because neonatal morbidity and mortality is such an important indicator of the quality of health care for mothers and children, and because data are needed to inform possible interventions to improve outcomes for newborns in the Ukraine. The authors have established early-onset perinatal mortality and morbidity in Ukraine and defined the current epidemiology of neonatal infections. These data can be used for benchmarking among units and international comparisons.

\section{CONCLUSIONS}

This study showing that the incidence rate of perinatal infections, as well as their associated impact on mortality, and presents a significant burden to the Ukraine. These findings suggest that it is time to consider systematic interventions to reduce neonatal infection incidence and mortality, including the potential of developing a global national surveillance networks. Routinely collected surveillance data, integrated with a patient administrative system, are of great value as a basis for studying the long-term consequences of neonatal infections. Burden estimates obtained in this study will be valuable in future evaluations of the cost-effectiveness of neonatal infection prevention programs.

\section{REFERENCES}

1. Tran H.T., Doyle L.W., Lee K.J. et al. A systematic review of the burden of neonatal mortality and morbidity in the ASEAN Region. WHO South East Asia J Public Health. 2012;1(3):239-248. doi:10.4103/22243151.207020.

2. Oestergaard M.Z., Inoue M., Yoshida S. et al. Neonatal mortality levels for 193 countries in 2009 with trends since 1990: a systematic analysis of progress, projections, and priorities. PLoS Med. 2011;8(8):e1001080. doi:10.1371/journal.pmed.1001080.

3. Martines J., Paul V.K., Bhutta Z.A. et al. Neonatal survival: a call for action. Lancet. 2005;365(9465):1189-1197. doi:10.1016/501406736(05)71882-1.

4. The United Nations Inter-Agency Group for Child Mortality Estimation (UN IGME), Report 2020. Levels and Trends in Child Mortality. https:// data.unicef.org/resources/levels-and-trends-in-child-mortality/ [accessed 28 May 2021]. 
5. WHO. Newborns: improving survival and well-being. https://www. who.int/news-room/fact-sheets/detail/newborns-reducing-mortality [accessed 11 May 2021].

6. Adams-Chapman I., Stoll B.J. Neonatal infection and long-term neurodevelopmental outcome in the preterm infant. Curr Opin Infect Dis. 2006;19(3):290-297. doi:10.1097/01.qc0.0000224825.57976.87.

7. Ostrander B., Bale J.F. Congenital and perinatal infections. Handb Clin Neurol. 2019;162:133-153. doi:10.1016/B978-0-444-64029-1.00006-0.

8. Stoll B.J., Hansen N. Infections in VLBW infants: studies from the NICHD Neonatal Research Network. Semin Perinatol. 2003;27(4):293-301. doi:10.1016/s0146-0005(03)00046-6.

9. May M., Daley A.J., Donath S. et al. Early onset neonatal meningitis in Australia and New Zealand, 1992-2002. Arch Dis Child Fetal Neonatal Ed. 2005;90(4):F324-F327. doi:10.1136/adc.2004.066134.

10. Isaacs D. Australasian Study Group For Neonatal Infections. A ten year, multicentre study of coagulase negative staphylococcal infections in Australasian neonatal units. Arch Dis Child Fetal Neonatal Ed. 2003;88(2):89-93. doi:10.1136/fn.88.2.f89.

11. Vergnano S., Buttery J., Cailes B. et al. Neonatal infections: Case definition and guidelines for data collection, analysis, and presentation of immunisation safety data. Vaccine. 2016; 34(49): 6038-6046. doi: 10.1016/j.vaccine.2016.03.046.

12. European Consensus Conference on Quality Assurance Indicators for Perinatal Care: report on a joint WHO/EURO-IMI meeting, 1993, Tübingen. Copenhagen, WHO Regional Office for Europe, 1994 (unpublished document).

13. United Nations Inter-agency Group for Child Mortality Estimation (UN IGME) 2020. https://data.unicef.org/topic/child-survival/neonatalmortality [accessed 11 May 2021].

14. Carey A.J., Duchon J., Della-Latta P. et al. The epidemiology of methicillin-susceptible and methicillin-resistant Staphylococcus aureus in a neonatal intensive care unit, 2000-2007. J Perinatol. 2010;30(2):135-9. doi: 10.1038/jp.2009.119.

15. Saha B.C., Kumari R., Sinha B.P. Clinical Outcome of Probing in Infants with Acute Dacryocystitis - A Prospective Study. J Clin Diagn Res. 2017;11(8):NC01-NC03. doi:10.7860/JCDR/2017/29033.10295.

16. Zhonghua Er Ke Za Zhi. Collaborative Study Group for Neonatal Bacterial Meningitis. 2018;56(6):421-428. doi:10.3760/cma.j.is sn.0578-1310.2018.06.004.

17. Fleischmann-Struzek C., Goldfarb D.M., Schlattmann P. et al. The global burden of paediatric and neonatal sepsis: a systematic review. Lancet Respir Med. 2018;6:223-30.

18. Sugai M.K., Gilmour S., Ota E., Shibuya K. Trends in perinatal mortality and its risk factors in Japan: Analysis of vital registration data, 19792010. Sci Rep. 2017;7:46681. doi: 10.1038/srep46681.

19. Song Y.H., Lee G.M., Yoon J.M. et al. Trends in Fetal and Perinatal Mortality in Korea (2009-2014): Comparison with Japan and the United States. J Korean Med Sci. 2017;32(8):1319-1326. doi: 10.3346/ jkms.2017.32.8.1319.

20. Wang H., Liddell C.A., Coates M.M. et al. Global, regional, and national levels of neonatal, infant, and under-5 mortality during 1990-2013: a systematic analysis for the Global Burden of Disease Study 2013. Lancet. 2014;384(9947):957-79. doi:10.1016/S0140-6736(14)60497-9.

21. Marushko R.V., Dudina 0.0. Modern aspects of perinatal mortality in Ukraine. Ukrainian Journal of Perinatology and Pediatrics. 2020;2(82): 76-85. doi 10.15574/PP.2020.82.76.
22. Fleischmann C., Reichert F., Cassini A. et al. Global incidence and mortality of neonatal sepsis: a systematic review and meta- analysis. Arch Dis Child, 2021;0:1-8. doi:10.1136/archdischild-2020-320217.

23. Al-Matary A., Heena H., AlSarheed A.S. et al. Characteristics of neonatal Sepsis at a tertiary care hospital in Saudi Arabia. J Infect Public Health. 2019;12(5):666-672. doi: 10.1016/j.jiph.2019.03.007.

24. Vergnano S., Menson E., Kennea N. et al. Neonatal infections in England: the NeonIN surveillance network. Arch Dis Child Fetal Neonatal Ed. 2011;96(1):F9-F14. doi: 10.1136/adc.2009.178798.

25. Lusyati S., van den Broek P., Sauer P.J. Neonatal sepsis in a neonatal intensive care unit in Indonesia. J Hosp Infect. 2009;71(4):383-385. doi:10.1016/j.jhin.2009.01.004.

We would like to thank all the nurses and physicians who contributed to the prevalence surveys.

This work is a fragment of a research study of the Scientific Research Laboratory of Shupyk National Healthcare University of Ukraine (Kyiv, Ukraine). Title: The scientific justification for measures to combat the resistance of microorganisms to antimicrobial drugs in Ukraine on the One Health approaches. State Registration Number: 0120U101440. Study period: 2020-2022. This work was funded by the Ministry of Health of Ukraine according to the plan of that research study. The authors did not receive any financial support from the manufacturers of medical instruments and drugs.

\section{ORCID and contributionship:}

Aidyn G. Salmanov: 0000-0002-4673-1154 A, C-F

Oleg M. Ishchak: $0000000296343635^{\text {B-F }}$

Serhii A. Dobarin: 0000-0002-9828-7921 B-D,F

Olena M. Susidko: 0000-0002-4840-0033 ${ }^{B-D, F}$

Olena V. Mosendz: 0000-0002-7392-7929 B-D, F

Svitlana M. Korniyenko: 0000-0003-3743-426X ${ }^{B-D, F}$

Oleksandr A. Voloshyn: 0000 0002-6586- $5449^{B-D, F}$

\section{Conflict of interest:}

The Authors declare no conflict of interest

\section{CORRESPONDING AUTHOR Aidyn G. Salmanov}

Shupyk National Healthcare University of Ukraine

9 Dorohozhytska St., 04112 Kyiv, Ukraine

tel: +380667997631

e-mail:mozsago@gmail.com

Received: 07.06 .2021

Accepted: 25.08 .2021

A - Work concept and design, B - Data collection and analysis, C - Responsibility for statistical analysis, D-Writing the article, E-Critical review, F-Final approval of the article 